\title{
Understanding the Reactivity of Ion-Encapsulated Fullerenes
}

\author{
Yago García-Rodeja, ${ }^{[a]}$ Miquel Solà, ${ }^{[b]}$ F. Matthias Bickelhaupt,${ }^{[c]}$ and Israel Fernández ${ }^{*[a]}$
}

Dedication ((optional))

\begin{abstract}
The influence of the encapsulation of an ion inside the $\mathrm{C}_{60^{-}}$ fullerenic cage on its exohedral reactivity has been explored by means of Density Functional Theory calculations. To this end, the Diels-Alder reaction between 1,3-cyclohexadiene and $\mathrm{M@C}_{60}\left(\mathrm{M}=\mathrm{Li}^{+}, \mathrm{Na}^{+}, \mathrm{K}^{+}\right.$, $\mathrm{Be}^{2+}, \mathrm{Mg}^{2+}, \mathrm{Al}^{3+}$ and $\mathrm{Cl}^{-}$) has been studied and compared to the analogous process involving the parent $\mathrm{C}_{60}$-fullerene. A significant enhancement of the Diels-Alder reactivity is found for those systems having an endohedral cation whereas a clear reduction of the reactivity is observed when an anion is encapsulated into the $\mathrm{C}_{60}$-cage. The origins of this reactivity trend have been quantitatively analyzed in detail using the Activation Strain Model of reactivity in combination with the Energy Decomposition Analysis method.
\end{abstract}

\section{Introduction}

Endohedral metallofullerenes (EMFs) constitute a general class of fullerenes which are characterized by the encapsulation of a transition metal fragment inside the fullerenic cage. ${ }^{[1,2]}$ Since the detection of La@C 60 by Smalley and co-workers in 1985, ${ }^{[3]}$ the chemistry of this type of fullerenes has experienced a remarkable development. As a result, a good number of novel EMFs, having interesting properties for potential applications in material science and biomedicine, have been prepared..$^{[1,2]}$

Closely related to these EMFs, ion-encapsulated fullerenes, i.e., fullerenes having an endohedral ion, have emerged as a new family of endohedral fullerenes quite recently. ${ }^{[4]}$ Although only $\mathrm{Li}^{+} @ \mathrm{C}_{60}$ has been experimentally isolated and fully characterized, it becomes clear that the encapsulation of an ion inside the fullerenic cage has a tremendous impact on the electronic properties of the fullerene. For instance, this cationic fullerene is reported to form the highly stable donor-acceptor

[a] Mr. Yago García-Rodeja, Dr. Israel Fernández

Departamento de Química Orgánica I and Centro de Innovación en

Química Avanzada (ORFEO-CINQA), Facultad de Ciencias

Químicas

Universidad Complutense de Madrid, 28040-Madrid (Spain)

E-mail: israel@quim.ucm.es

[b] Prof. Dr. Miquel Solà

Institut de Química Computacional i Catàlisi and Departament de Química

Universitat de Girona, C/ Maria Aurèlia Campany 6, 17003-Girona (Spain)

[c] Prof. Dr. Matthias Bickelhaupt

Department of Theoretical Chemistry and Amsterdam Center for Multiscale Modeling (ACMM) and VU University, De Boelelaan 1083, 1081 HV Amsterdam, and Institute for Molecules and Materials (IMM), Radboud University Nijmegen, Heyendaalseweg 135, NL-6525 AJ Nijmegen (The Netherlands)

Supporting information for this article is given via a link at the end of the document.((Please delete this text if not appropriate))
$\mathrm{Li}^{+} @ \mathrm{C}_{60} \subset[10] \mathrm{CPP}$ supramolecular nanocarbon structure (CPP = cycloparaphenylene) due to the strong charge-transfer interaction between [10]CPP and $\mathrm{Li}^{+} @ \mathrm{C}_{60} .^{[5]}$ Moreover, $\mathrm{Li}^{+} @ \mathrm{C}_{60}$ has been also found to have interesting non-linear optical properties, ${ }^{[6]}$ to be a molecular switch at low temperatures, ${ }^{[7]}$ and to be an efficient photosensitizer for the generation of singlet oxygen in water. ${ }^{[8]}$

Not surprisingly, the presence of the lithium cation also modifies the exohedral reactivity of the $\mathrm{C}_{60}$ moiety..$^{[9,10]}$ Indeed, it was found that $\mathrm{Li}^{+} @ \mathrm{C}_{60}$ shows greatly enhanced reactivity in photo-induced electron-transfer reductions with electron donors as compared to hollow $\mathrm{C}_{60 .}{ }^{[11]}$ Strikingly, the Diels-Alder (DA) cycloaddition reactions between cyclopentadiene or 1,3cyclohexadiene and $\mathrm{Li}^{+} @ \mathrm{C}_{60}$ were reported to be significantly faster than the analogous processes involving the parent $\mathrm{C}_{60^{-}}$ fullerene. ${ }^{[10]}$ Thus, the observed activation barrier for the DA reaction of $\mathrm{Li}^{+} @ \mathrm{C}_{60}$ and $\mathrm{C}_{6} \mathrm{H}_{8}(11.0 \mathrm{kcal} / \mathrm{mol})$ was about $6 \mathrm{kcal} / \mathrm{mol}$ lower than that for the reaction involving empty $\mathrm{C}_{60}(16.8$ $\mathrm{kcal} / \mathrm{mol}) .^{[10 \mathrm{~b}]}$ This enhanced DA reactivity has been qualitatively attributed to the reduction of the HOMO(diene)-LUMO(fullerene) gap as a consequence of the stabilization of the $\mathrm{Li}^{+} @ \mathrm{C}_{60}-\mathrm{LUMO}$ $\left(\mathrm{E}_{\text {LUMO }}=-3.74 \mathrm{vs}-2.70 \mathrm{eV}\right.$, for $\mathrm{Li}^{+} @ \mathrm{C}_{60}$ and $\mathrm{C}_{60}$, respectively). ${ }^{[10 \mathrm{~b}]}$ Despite that, we want to point out that, as repeatedly reported, ${ }^{[12]}$ the use of Frontier Molecular Orbital (FMO) arguments to rationalize the reactivity, particularly in pericyclic reactions, may lead to misleading conclusions as the FMO interactions are exclusively computed at the equilibrium geometries of the reactants, therefore ignoring those interactions occurring at the transition-state region or at any other point along the reaction coordinate.

Fortunately, the introduction of the Activation Strain Model $(A S M)^{[13]}$ of reactivity in combination with the Energy Decomposition Analysis (EDA $)^{[14]}$ method has allowed us to gain quantitative insight into different fundamental processes in organic $^{[15]}$ and organometallic ${ }^{[16]}$ chemistry along the entire reaction coordinate. This approach has been particularly useful to quantitatively understanding the Diels-Alder reactivity and selectivity of empty and endohedral fullerenes ${ }^{[17,18]}$ as well as strongly related curved and planar polycyclic aromatic hydrocarbons. ${ }^{[19]}$ For this reason, we decided to apply the combined ASM-EDA method to explore the influence of an encapsulated endohedral ion $\left(\mathrm{M}=\mathrm{Li}^{+}, \mathrm{Na}^{+}, \mathrm{K}^{+}, \mathrm{Cl}^{-}, \mathrm{Be}^{2+}, \mathrm{Mg}^{2+}\right.$, $\mathrm{Al}^{3+}$ ) on the exohedral reactivity of the $\mathrm{C}_{60}$-fullerenic cage. To this end, we will consider the Diels-Alder reactions involving these ionencapsulated $\mathrm{M@C}_{60}$ species and 1,3-cyclohexadiene (experimentally studied for $\left.\mathrm{Li}^{+} @ \mathrm{C}_{60}\right)^{[10 \mathrm{~b}]}$ and compare them with the process involving the parent $\mathrm{C}_{60}$-fullerene. The results of our ASM-EDA study will complement and expand previous theoretical studies $^{[20]}$ on similar cationic species (based mainly on FMO arguments) aiming at rationalizing the poorly understood reactivity of this genuine family of fullerenes. 


\section{Computational Details}

Geometry optimizations of the molecules were performed without symmetry constraints using the Gaussian03 ${ }^{[21]}$ optimizer together with Turbomole 6.6 ${ }^{[22]}$ energies and gradients at the BP86 ${ }^{[23]} /$ def2-SVP[24] level of theory using the D3 dispersion correction suggested by Grimme et al. ${ }^{[25]}$ and the resolution-of-identity (RI) approximation. ${ }^{[26]}$ This level is denoted RI-BP86-D3/def2-SVP and has been selected because it provided very good results for Diels-Alder reactions involving related fullerenes. ${ }^{[17,18]}$ Reactants and cycloadducts were characterized by frequency calculations, and have positive definite Hessian matrices. Transition states (TSs) show only one negative eigenvalue in their diagonalized force constant matrices, and their associated eigenvectors were confirmed to correspond to the motion along the reaction coordinate under consideration using the Intrinsic Reaction Coordinate (IRC) method. ${ }^{[27]}$ Single-point energy refinements were carried out using the D3-corrected metahybrid M06$2 X^{[28]}$ functional in conjunction with the triple- $\zeta$-quality def2-TZVPP basis sets. ${ }^{[24]}$ This level is therefore denoted M06-2X-D3/def2-TZVPP//RI-BP86D3/def2-SVP.

\section{Activation Strain Analyses of Reaction Profiles}

The activation strain model of reactivity, also known as distortion/interaction model, ${ }^{[29]}$ is a fragment approach to understanding chemical reactions, in which the height of reaction barriers is described and understood in terms of the original reactants. ${ }^{9}$ The ASM is a systematic extension of the fragment approach from equilibrium structures to TSs as well as non-stationary points, e.g., points along a reaction coordinate. Thus, the potential energy surface $\Delta E(\zeta)$ is decomposed, along the reaction coordinate $\zeta$, into the strain $\Delta E_{\text {strain }}(\zeta)$ associated with deforming the individual reactants plus the actual interaction $\Delta E_{\text {int }}(\zeta)$ between the deformed reactants (eq. 1):

$\Delta E(\zeta)=\Delta E_{\text {strain }}(\zeta)+\Delta E_{\text {int }}(\zeta)$

(eq. 1)

The strain $\Delta E_{\text {strain }}(\zeta)$ is determined by the rigidity of the reactants and by the extent to which groups must reorganize in a particular reaction mechanism, whereas the interaction $\Delta E_{\text {int }}(\zeta)$ between the reactants depends on their electronic structure and on how they are mutually oriented as they approach each other. It is the interplay between $\Delta E_{\text {strain }}(\zeta)$ and $\Delta E_{\text {int }}(\zeta)$ that determines if and at which point along $\zeta$ a barrier arises, namely, at the point where $\mathrm{d} \Delta E_{\text {strain }}(\zeta) / \mathrm{d} \zeta=-\mathrm{d} \Delta E_{\text {int }}(\zeta) / \mathrm{d} \zeta$.

In the cycloaddition reactions considered herein, the reaction coordinate is defined as the projection of the IRC onto the forming $C \cdots C$ distance between the carbon atom of the fullerene and the carbon atom of the diene. This reaction coordinate $\zeta$ undergoes a well-defined change in the course of the reaction from the initially formed reactant complexes to the equilibrium C...C distance in the corresponding TSs.

\section{Energy Decomposition Analysis}

The interaction $\Delta E_{\text {int }}(\zeta)$ between the strained reactants can be further partitioned with the help of the Energy Decomposition Analysis (EDA) method. ${ }^{[14]}$ Within this approach, this term is decomposed into the following physically meaningful terms (eq. 2):

$\Delta E_{\text {int }}(\zeta)=\Delta V_{\text {elstat }}(\zeta)+\Delta E_{\text {pauli }}(\zeta)+\Delta E_{\text {orb }}(\zeta)+\Delta E_{\text {disp }}(\zeta)$

The term $\Delta V_{\text {elstat }}$ corresponds to the classical electrostatic interaction between the unperturbed charge distributions of the deformed reactants and is usually attractive. The Pauli repulsion $\Delta E_{\text {Pauli }}$ comprises the destabilizing interactions between occupied orbitals and is responsible for any steric repulsion. The orbital interaction $\Delta E_{\text {orb }}$ accounts for electron-pair bonding, charge transfer (interaction between occupied orbitals on one moiety with unoccupied orbitals on the other, including HOMO-LUMO interactions), and polarization (empty-occupied orbital mixing on one fragment due to the presence of another fragment). Finally, the $\Delta E_{\text {disp }}$ term takes into account the interactions which are due to dispersion forces. Moreover, the NOCV (Natural Orbital for Chemical Valence) ${ }^{[30]}$ extension of the EDA method has been also used to further partitioning the $\Delta E_{\text {orb }}$ term. The EDA-NOCV approach ${ }^{[31]}$ provides pairwise energy contributions for each pair of interacting orbitals to the total bond energy.

The program package ADF 2016.01 ${ }^{[32]}$ was used for the EDA-NOCV calculations at the BP86-D3 level, in conjunction with a triple- $\zeta$-quality basis set using uncontracted Slater-type orbitals (STOs) augmented by two sets of polarization functions with a frozen-core approximation for the core electrons. Auxiliary sets of s, p, d, f, and g STOs were used to fit the molecular densities and to represent the Coulomb and exchange potentials accurately in each SCF cycle. ${ }^{[33]}$ Scalar relativistic effects were incorporated by applying the zeroth-order regular approximation (ZORA). ${ }^{[34]}$ This level of theory is denoted ZORA-BP86-D3/TZ2P//RIBP86-D3/def2-SVP.

\section{Results and Discussion}

We first explored the Diels-Alder reactions between 1,3cyclohexadiene and group 1 containing cationic $\mathrm{M}^{+} @ \mathrm{C}_{60}\left(\mathrm{M}^{+}=\mathrm{Li}^{+}\right.$, $\mathrm{Na}^{+}, \mathrm{K}^{+}$) and the parent $\mathrm{C}_{60}$ fullerenes. Note that we have focused only on the cycloaddition reactions involving the [6,6]-pyracylenic bond of the $\mathrm{C}_{60}$-cage because this bond was found previously to be favored over the [5,6]-corannulenic bond for either the parent $\mathrm{C}_{60}{ }^{[17]}$ or the ion-encapsulated $\mathrm{M}^{+} @ \mathrm{C}_{60}$ fullerenes $\left(\mathrm{M}^{+}=\right.$group 1 element). [20a] In agreement with previous calculations, ${ }^{[10 b, 20 a]}$ the computed reaction profiles depicted in Figure 1 indicate that in all cases the cycloaddition reaction occurs concertedly via an initial reactant complex (RC) which is transformed into the corresponding cycloadduct (CA) via a highly synchronous transition state (TS, see Figure 2). From the data in Figure 1, it is confirmed that the encapsulation of the group 1 cation inside the fullerenic cage induces a significant decrease of the activation barrier $\left(\Delta E_{\mathrm{a}}=17.1>12.2>11.8>10.4 \mathrm{kcal} / \mathrm{mol}\right.$, for $\mathrm{M}=$ none, $\mathrm{Li}^{+}, \mathrm{Na}^{+}, \mathrm{K}^{+}$, respectively). In addition, the process also becomes more a more exothermic when going down in the group $\left(\Delta E_{\mathrm{R}}=-\right.$ $29.8<-35.0<-35.6<-36.6 \mathrm{kcal} / \mathrm{mol}$, for $\mathrm{M}=$ none, $\mathrm{Li}^{+}, \mathrm{Na}^{+}, \mathrm{K}^{+}$, respectively). In sharp contrast, the presence of an anion in the cage $\left(\mathrm{Cl}^{-}\right.$in this study) provokes the opposite effect, i.e. the process becomes kinetically $\left(\Delta E_{\mathrm{a}}=20.9 \mathrm{kcal} / \mathrm{mol}\right)$ and thermodynamically $\left(\Delta E_{\mathrm{R}}=-26.4 \mathrm{kcal} / \mathrm{mol}\right)$ less favored than that involving free $\mathrm{C}_{60}$. We want to point out that our computed M062X-D3/def2-TZVPP//RI-BP86-D3/def2-SVP activation energies for the processes involving $\mathrm{C}_{60}$ and $\mathrm{Li}^{+} @ \mathrm{C}_{60}$ are in very good agreement with the available experimental data (17.1 and 12.2 $\mathrm{kcal} / \mathrm{mol}$ versus 16.8 and $11.0 \mathrm{kcal} / \mathrm{mol}$, respectively), ${ }^{[10 \mathrm{~b}]}$ which validates the selected computational method for this study. It is also worth noting that $\mathrm{Li}^{+} @ \mathrm{C}_{60}$ is the only system that places the encapsulated ion off-centered in all stationary points located except in the reactants. This result is not surprising in view of previous studies showing the high mobility of $\mathrm{Li}^{+}$in $\mathrm{Li}^{+} @ \mathrm{C}_{60} .^{[7,35]}$ 


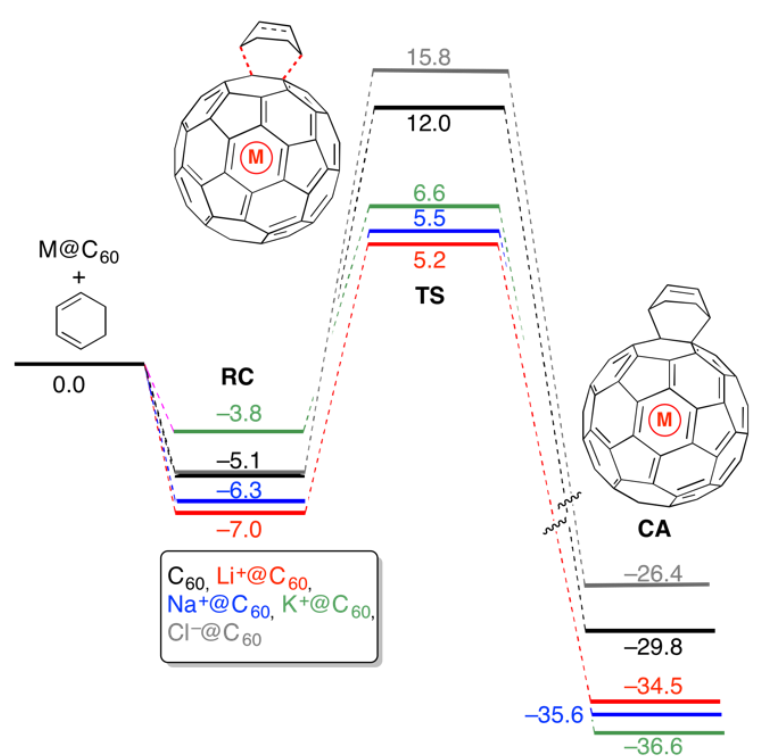

Figure 1. Computed reaction profile for the [4+2]-cycloaddition reaction between 1,3-cyclohexadiene and ${\mathrm{M} @ \mathrm{C}_{60}}_{6 p}$ species. Relative energies are given in $\mathrm{kcal} / \mathrm{mol}$. All data have been computed at the M06-2X-D3/def2-TZVPP//RIBP86-D3/def2-SVP level.

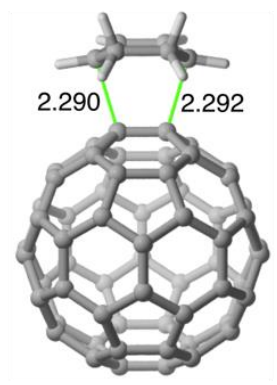

TS- $\mathrm{C}_{60}$

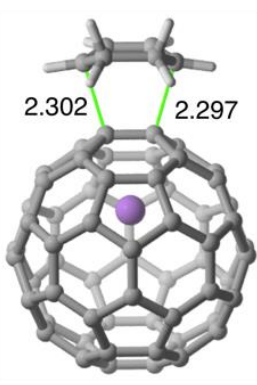

TS-Li+@ $\mathrm{C}_{60}$

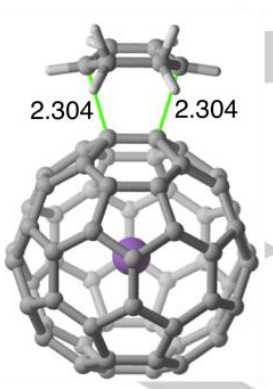

TS-Na+@ $\mathrm{C}_{60}$

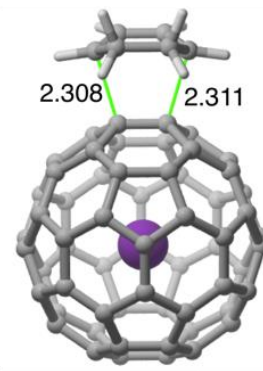

TS-K+@ $\mathbf{C}_{60}$

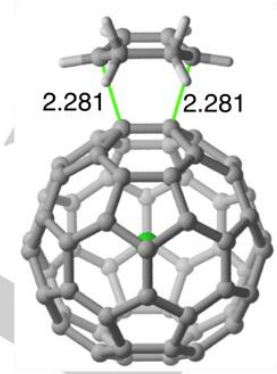

TS-Cl-@ 60
Figure 2. Fully optimized geometries (RI-BP86-D3/def2-SVP level) of the transition states involved in the Diels-Alder cycloaddition reactions between 1,3cyclohexadiene and $\mathrm{M} @ 60_{60}$ species. Bond distances are given in angstroms.
Interestingly, there is a clear linear relationship between the computed activation and reaction energies (correlation coefficient of 0.99 , standard deviation 0.24 and slope of 1.01 , Figure 3 ), therefore satisfying the empirical relationship given by Brønsted, Dimroth, Marcus, and Bell-Evans-Polanyi (also known as the Bema Hapothle relationship). ${ }^{[36]}$ The studied Diels-Alder also follows the Hammond-Leffer postulate. ${ }^{[37]}$ As stated by this postulate, more reactant-like TS are expected for more exothermic transformations. Indeed, closer inspection of the C...C forming distances of the optimized transition states in Figure 2 nicely confirms that earlier transition states $\left(\mathrm{M}^{+} @ \mathrm{C}_{60}\right)$ are associated with higher exothermicities whereas less exothermic cycloadditions involve later transition states $\left(\mathrm{C}_{60}\right.$ and $\left.\mathrm{Cl}^{-} @ \mathrm{C}_{60}\right)$. A similar linear correlation was also observed for the Diels-Alder reactions involving cyclopentadiene and the strongly related endohedral $\mathrm{Ng}_{2} @ \mathrm{C}_{60}\left(\mathrm{Ng}=\right.$ noble gas) fullerenes, ${ }^{[18 \mathrm{a}]}$ therefore indicating reactivity likeness of these species.

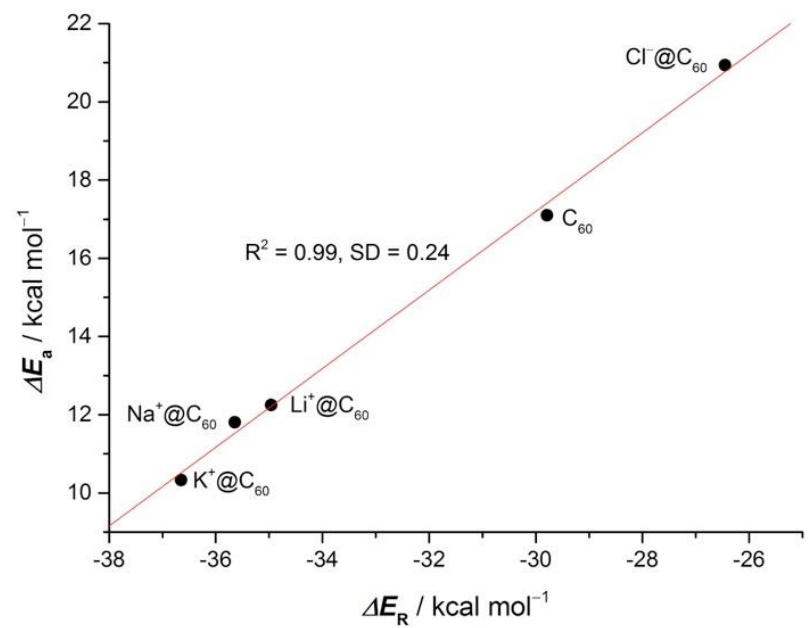

Figure 3. Plot of the reaction energies $\left(\Delta E_{\mathrm{R}}\right)$ vs activation energies $\left(\Delta E_{\mathrm{a}}\right)$ for the Diels-Alder cycloaddition reactions between 1,3-cyclohexadiene and M@ $\mathrm{C}_{60}$ species. All data have been computed at the M06-2X-D3/def2-TZVPP//RIBP86-D3/def2-SVP level.

The physical factors governing the above discussed reactivity trend were next quantitatively analyzed by means of the Activation Strain Model (ASM) of reactivity. To this end, we compared the [4+2]-cycloadditions involving both a cationic $\left(\mathrm{Li}^{+} @ \mathrm{C}_{60}\right)$ and an anionic $\left(\mathrm{Cl}^{-} @ \mathrm{C}_{60}\right)$ system with that involving the parent $\mathrm{C}_{60}$. Figure 4 shows the computed activation strain diagrams (ASD) for the cycloaddition reactions between 1,3-cyclohexadiene and $\mathrm{C}_{60}$ (solid lines), $\mathrm{Li}^{+} @ \mathrm{C}_{60}$ (dotted lines) and $\mathrm{Cl}^{-} @ \mathrm{C}_{60}$ (dashed lines) from the respective reactant complexes up to the corresponding transition states. The shape of the different curves is rather similar in the sense that for all systems the strain energy $\left(\Delta E_{\text {strain }}\right)$ monotonically increases along the reaction coordinate whereas the interaction energy ( $\left.\Delta E_{\text {int }}\right)$ between the deformed reactants only becomes more and more stabilizing when reaching the transition state region. This particular behavior is shared not only 
by related DA cycloadditions reactions ${ }^{[15 i]}$ but also by other types of pericyclic reactions. ${ }^{[15 \mathrm{e}]}$

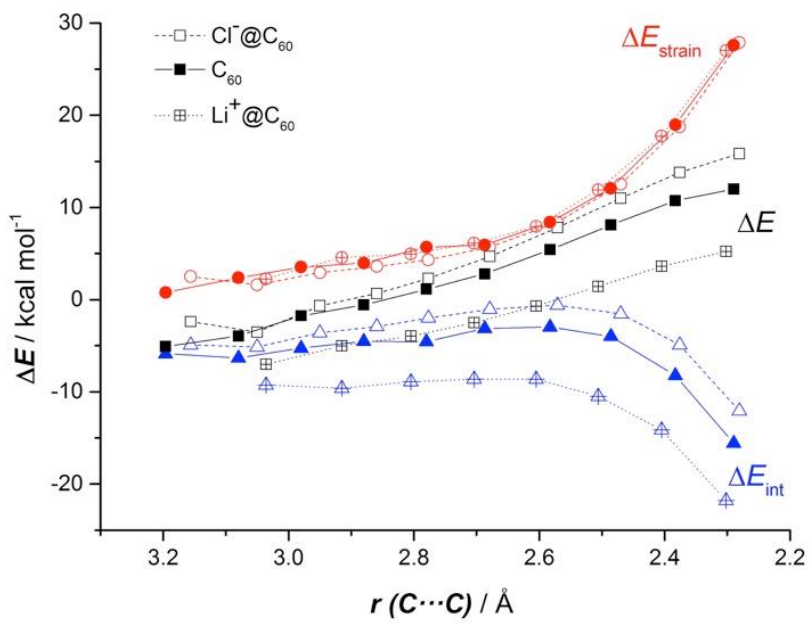

Figure 4. Activation strain diagrams of the [4+2]-cycloaddition reaction between 1,3-cyclohexadiene and $\mathrm{C}_{60}$ (solid lines), $\mathrm{Li}^{+} @ \mathrm{C}_{60}$ (dotted lines) and $\mathrm{Cl}^{-} @ \mathrm{C}_{60}$ (dashed lines) along the reaction coordinate projected onto the forming $\mathrm{C}$... bond distance. All data have been computed at the M06-2X-D3/def2TZVPP//RI-BP86-D3/def2-SVP level.

Comparison of the different energy contributors to the total energy clearly reveals that the strain energy is not at all responsible for the different reactivity of the $\mathrm{M@C}_{60}$ systems as the $\Delta E_{\text {strain }}$ term is nearly identical along the entire reaction coordinate for all species. Instead, the interaction energy between the deformed reactants becomes the sole factor that determines the observed reactivity trend. As depicted in Figure 4, the interaction energy between the reactants is, along the entire transformation, clearly stronger for the cationic system $\mathrm{Li}^{+} @ \mathrm{C}_{60}$ than for the processes involving the parent $\mathrm{C}_{60}$ or the anionic $\mathrm{Cl}^{-}$ $@ \mathrm{C}_{60}$ fullerenes. For instance, at the same $\mathrm{C} \cdots \mathrm{C}$ forming distance of $2.4 \AA$, the difference in the interaction energy $\Delta \Delta E_{\text {int }}=8.6$ and $12.3 \mathrm{kcal} / \mathrm{mol}$ (values comparing the reactions involving $\mathrm{Li}^{+} @ \mathrm{C}_{60}$ vs $\mathrm{C}_{60}$, and $\mathrm{Li}^{+} @ \mathrm{C}_{60} \mathrm{vs}^{-} @ \mathrm{C}_{60}$, respectively) roughly matches the computed total energy differences between these transformations $(\Delta \Delta E=7.0$ and $10.9 \mathrm{kcal} / \mathrm{mol})$. Therefore, it can be safely concluded that the presence of an endohedral cation in the $\mathrm{C}_{60}$-cage leads to a significant enhancement of the exohedral Diels-Alder reactivity (as compared to free $\mathrm{C}_{60}$ ) as a consequence of a much stronger interaction between the reactants from the initially formed reactant complex up to the corresponding transition state. In contrast, an anion inside the fullerenic cage produces the opposite effect, i.e. it makes the interaction energy between the reactants comparatively weaker than in the process involving the parent $\mathrm{C}_{60}$-fullerene therefore increasing the barrier of the transformation.

Further quantitative insight into the different contributors to the total interaction energy between the deformed reactants can be gained by using the EDA method. As graphically shown in Figure 5 , which illustrates the variation of the different EDA terms again from the respective reactant complexes up to the transition states for the processes involving $\mathrm{C}_{60}$ (solid lines) and $\mathrm{Li}^{+} @ \mathrm{C}_{60}$ (dotted lines) and $\mathrm{Cl}^{-} @ \mathrm{C}_{60}$ (dashed lines), it is clear that the stronger interaction energy computed for the $\mathrm{Li}^{+} @ \mathrm{C}_{60}$ system derives almost exclusively from a much stronger orbital attraction between the reactants along the entire reaction coordinate. For instance, as the same forming $\mathrm{C} \cdots \mathrm{C}$ distance of $2.4 \AA$, the $\Delta E_{\text {orb }}$ term increases in the order $-35.8 \mathrm{kcal} / \mathrm{mol}\left(\mathrm{Cl}^{-} @ \mathrm{C}_{60}\right)<-38.8$ $\mathrm{kcal} / \mathrm{mol}\left(\mathrm{C}_{60}\right)<-45.7 \mathrm{kcal} / \mathrm{mol}\left(\mathrm{Li}^{+} @ \mathrm{C}_{60}\right)$, therefore following the same trend as the interaction energy as well as the computed activation barriers. The $\mathrm{Li}^{+} @ \mathrm{C}_{60}$ system also benefits from a less destabilizing Pauli repulsion, $\Delta E_{\text {Pauli, albeit to a much lesser extent }}$ as compared to the $\Delta E_{\text {orb }}$ term: $\Delta E_{\text {Pauli }}=78.8 \mathrm{kcal} / \mathrm{mol}\left(\mathrm{Cl}^{-} @ \mathrm{C}_{60}\right)$ $>76.0 \mathrm{kcal} / \mathrm{mol}\left(\mathrm{C}_{60}\right)>73.3 \mathrm{kcal} / \mathrm{mol}\left(\mathrm{Li}^{+} @ \mathrm{C}_{60}\right)$. This increase in the $\Delta E_{\text {Pauli }}$ term is very likely due to the somewhat larger electron density of the $\mathrm{C}_{60}$ cage when going from $\mathrm{Li}^{+} @ \mathrm{C}_{60}$ to hollow $\mathrm{C}_{60}$ and to $\mathrm{Cl}^{-} @ \mathrm{C}_{60}$.

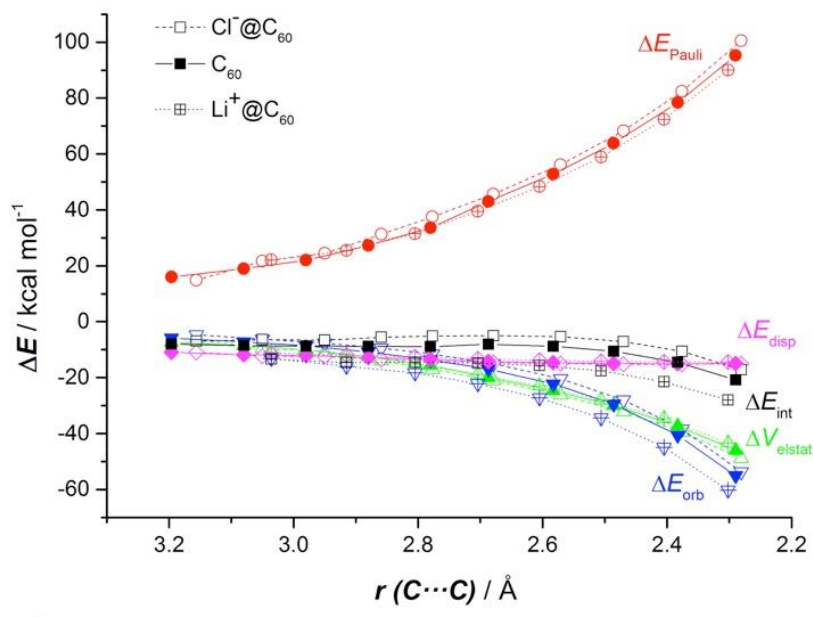

Figure 5. Decomposition of the interaction energy for the [4+2]-cycloaddition reactions between 1,3-cyclohexadiene and $\mathrm{C}_{60}$ (solid lines), $\mathrm{Li}^{+} @ \mathrm{C}_{60}$ (dotted lines) and $\mathrm{Cl}^{-} @ \mathrm{C}_{60}$ (dashed lines) along the reaction coordinate projected onto the forming $\mathrm{C} \cdots \mathrm{C}$ bond distance. All data have been computed at the ZORABP86-D3/TZ2P//RI-BP86-D3/def2-SVP level.

As expected, the decisive role of the $\Delta E_{\text {orb }}$ is consistent with the stabilization of the LUMO in the cationic species $(-7.60,-7.57$ and -7.57 eV for $\mathrm{Li}^{+} @ \mathrm{C}_{60}, \mathrm{Na}^{+} @ \mathrm{C}_{60}$ and $\mathrm{K}^{+} @ \mathrm{C}_{60}$, respectively) as compared to $\mathrm{C}_{60}(-4.42 \mathrm{eV})$ and $\mathrm{Cl}^{-} @ \mathrm{C}_{60}(-1.30 \mathrm{eV})$. Despite that, the EDA-NOCV method was also applied to quantitatively assess the contributions of the specific molecular orbitals of the reactants in the cycloaddition. The EDA-NOCV method indicates that two main donor-acceptor molecular orbital interactions dominate the total orbital attractions in this process, i.e. the $\Pi$ (diene) $\rightarrow \Pi^{*}$ (fullerene) and the reverse $\pi($ fullerene $) \rightarrow \pi^{*}$ (diene) interactions (see Figure 6 , charge flow is red $\rightarrow$ blue). As expected for a normal electronic demand, the former interaction is higher than the reverse interaction (i.e. $\left.\Delta E\left(\rho_{1}\right)>\Delta E\left(\rho_{2}\right)\right)$. This holds true even for the cycloaddition reaction involving $\mathrm{Cl}^{-} @ \mathrm{C}_{60}$, although in this case the difference between both interactions is much lower. Not surprisingly, the $\pi$ (diene) $\rightarrow \pi^{*}$ (fullerene) interaction trend is similar to that computed for the total $\Delta E_{\text {orb }}$ term: the $\Delta E\left(\rho_{1}\right)$ term increases in the order $-13.7 \mathrm{kcal} / \mathrm{mol}\left(\mathrm{Cl}^{-} @ \mathrm{C}_{60}\right)$ $<-18.1 \mathrm{kcal} / \mathrm{mol}\left(\mathrm{C}_{60}\right)<-25.5 \mathrm{kcal} / \mathrm{mol}\left(\mathrm{Li}^{+} @ \mathrm{C}_{60}\right)$. At variance, 
the reverse interaction follows the opposite trend (see Figure 6). Therefore, we can now conclude that the observed enhanced Diels-Alder reactivity of cation-encapsulated fullerenes finds its origin mainly in a much stronger $\pi$ (diene) $\rightarrow \pi^{*}$ (fullerene) interaction, which in turn is translated into a more stabilizing orbital interaction between the deformed reactants and ultimately, into a much stronger interaction energy between them along the entire reaction coordinate.
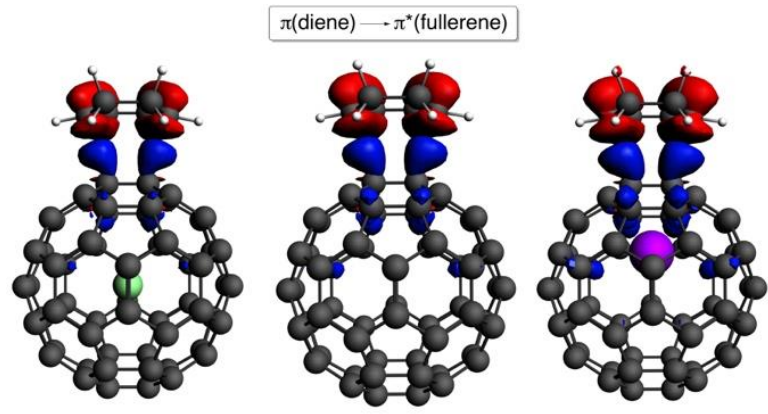

$\Delta \mathrm{E}\left(\rho_{1}\right)=-13.7 \mathrm{kcal} / \mathrm{mol}$

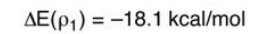

$\Delta \mathrm{E}\left(\rho_{1}\right)=-25.5 \mathrm{kcal} / \mathrm{mol}$

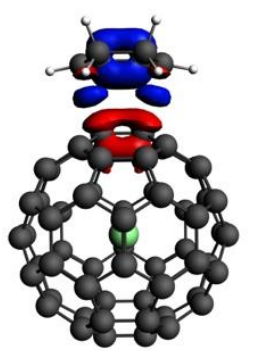

$\Delta \mathrm{E}\left(\rho_{2}\right)=-8.3 \mathrm{kcal} / \mathrm{mol}$ $\mathrm{Cl}-\mathrm{C}_{60}$

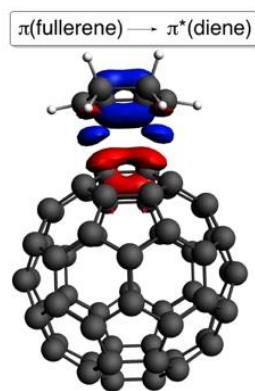

$\Delta \mathrm{E}\left(\rho_{2}\right)=-6.4 \mathrm{kcal} / \mathrm{mol}$ $\mathrm{C}_{60}$

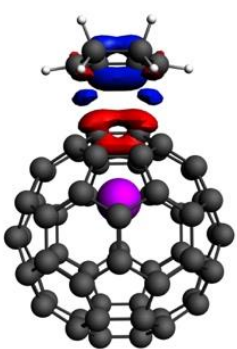

$\Delta \mathrm{E}\left(\rho_{2}\right)=-4.9 \mathrm{kcal} / \mathrm{mol}$ $\mathbf{L i}^{+} @ \mathbf{C}_{60}$
Figure 6. Plot of the deformation densities $\Delta \rho$ of the pairwise orbital interactions between 1,3-cyclohexadiene and $\mathrm{C}_{60}$ (middle), $\mathrm{Li}^{+} @ \mathrm{C}_{60}$ (right) and $\mathrm{Cl}^{-} @ \mathrm{C}_{60}$ (left) and associated stabilization energies $\Delta E$ in $\mathrm{kcal} / \mathrm{mol}$. The color code of the charge flow is red $\rightarrow$ blue.

To complete this study, we were finally curious to explore the effect of the encapsulation of multiply charged cations $\left(\mathrm{Be}^{2+}, \mathrm{Mg}^{2+}\right.$ and $\mathrm{Al}^{3+}$ ) in the $\mathrm{C}_{60}$-cage on the $[6,6]$-cycloaddition reaction with 1,3-cyclohexadiene. Different to the processes involving $\mathrm{M}^{+} @ \mathrm{C}_{60}$ ( $\mathrm{M}=$ group 1 cation, see above), our calculations suggest that the [4+2]-cycloaddition reactions involving $\mathrm{Be}^{2+} @ \mathrm{C}_{60}, \mathrm{Mg}^{2+} @ \mathrm{C}_{60}$ and $\mathrm{Al}^{3+} @ \mathrm{C}_{60}$ proceed stepwise via zwitterionic intermediates (INT) instead of in a concerted manner (see Figures 7 and 8). Indeed, all our attempts to locate a concerted reaction pathway for the formation of the corresponding cycloadducts met with no success. Similarly, the possibility of a stepwise process involving diradical intermediates instead of these zwitterionic species can be also ruled out because no such intermediates were located on the potential energy surface either. Similar zwitterionic intermediates have been previously reported in the cis-trans isomerization of optically pure endohedral $\mathrm{H}_{2} \mathrm{O} @ \mathrm{C}_{60}$ fulleropyrrolidines. ${ }^{[38]}$

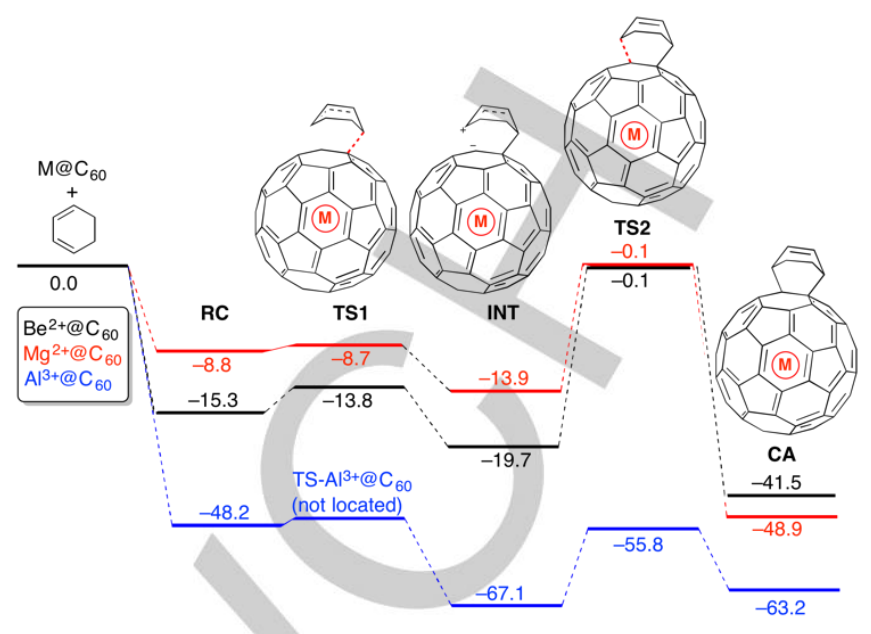

Figure 7. Computed reaction profile (not drawn to scale) for the [4+2]cycloaddition reaction between 1,3-cyclohexadiene and $\mathrm{M}_{6} \mathrm{C}_{60}$ species. Relative energies are given in $\mathrm{kcal} / \mathrm{mol}$. All data have been computed at the M06-2X-D3/def2-TZVPP//RI-BP86-D3/def2-SVP level.

This different behavior can be ascribed to the high polarization of the $\mathrm{C}_{60}$-cage induced by these di- and trications that results in a much stronger interaction between the reactants as compared to the group-1 cations. This fact becomes evident when comparing the energies and optimized geometries of the initial reactants complexes. Thus, whereas the RCs involving the group- 1 cations lie only -3.8 to $-7.0 \mathrm{kcal} / \mathrm{mol}$ below the separate reactants (see Figure 1), the group 2-RCs are -15.3 and -8.8 $\mathrm{kcal} / \mathrm{mol}$ (for $\mathrm{Be}^{2+}$ and $\mathrm{Mg}^{2+}$, respectively) below the reactants. The situation is even much more drastic for the trication $\mathrm{Al}^{3+}$, where the corresponding RC lies ca. $-50 \mathrm{kcal} / \mathrm{mol}$ below the separate reactants. Once again, this is in line with the LUMO energies computed for these species $(-11.3,-11.8$ and $-15.4 \mathrm{eV}$ for $\mathrm{Be}^{2+} @ \mathrm{C}_{60}, \mathrm{Mg}^{2+} @ \mathrm{C}_{60}, \mathrm{Al}^{3+} @ \mathrm{C}_{60}$, respectively), which are markedly lower (i.e. more negative) than those computed for the group 1 cationic analogues. In addition, this polarization greatly approximates the reactive carbon atoms of each reactant, i.e. whereas both forming C...C bond distances are ca. $3.1 \AA$ in the RCs involving group-1 cations, a significantly shorter C...C distance (ranging ca. 2.5-2.8 $\AA$ ) was computed for the corresponding multiply charged counterparts (see Figure 8). As a result of the asymmetry (i.e. different $\mathrm{C} \cdots \mathrm{C}$ distances) and close proximity of the reactants, the activation barrier associated with the $\mathrm{C}-\mathrm{C}$ bond formation (via TS1) is rather low $(<2 \mathrm{kcal} / \mathrm{mol}$ ) which provokes the observed switch from a concerted to a stepwise reaction mechanism. ${ }^{[39]}$ The formation of the second C$\mathrm{C}$ bond (via TS2) is, at variance, associated with a much higher activation barrier $\left(\Delta E_{\mathrm{a}} \approx 11-19 \mathrm{kcal} / \mathrm{mol}\right.$, see Figure 7$)$. These findings nicely confirm that the encapsulation of ions inside the fullerenic cage may induce a significant modification of the electronic nature of the fullerene which has a tremendous influence on the exohedral reactivity of the system. 


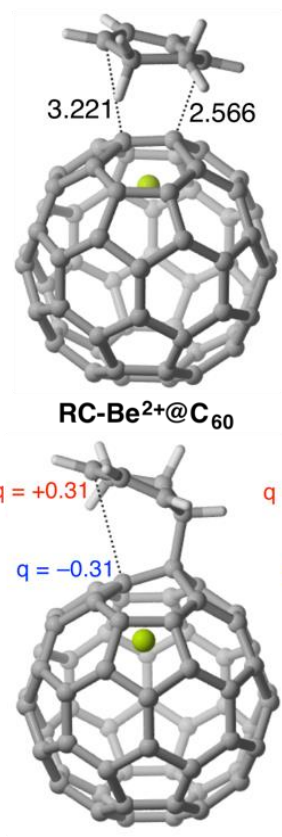

INT-Be $2+@ C_{60}$
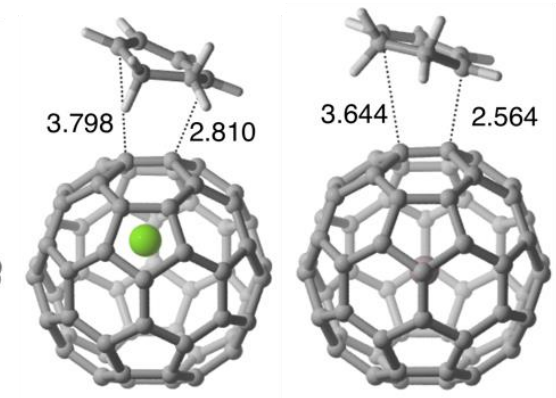

RC-Mg2+@ $\mathbf{C}_{60}$

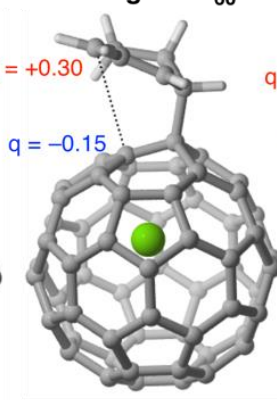

INT-Mg ${ }^{2+@ C_{60}}$

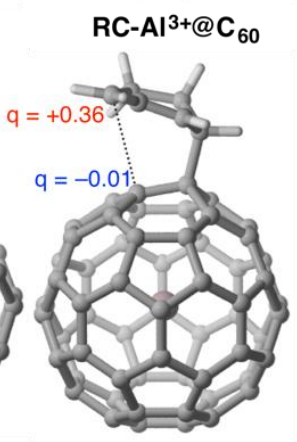

INT-AI3+@ $\mathbf{C}_{60}$

Figure 8. Fully optimized geometries (RI-BP86-D3/def2-SVP level) of the reactant complexes (top) and intermediates (bottom) involved in the Diels-Alder cycloaddition reactions between 1,3-cyclohexadiene and $\mathrm{M}_{0} \mathrm{C}_{60}$ species. Bond distances are given in angstroms. NBO-charges of the zwitterions are also shown.

\section{Conclusions}

From the computational study reported herein, it can be concluded that the $[6,6]$-regioselective Diels-Alder cycloaddition reactions between 1,3-cyclohexadiene and ion-encapsulated fullerenes of the type $\mathrm{M@C}_{60}\left(\mathrm{M}=\mathrm{Li}^{+}, \mathrm{Na}^{+}, \mathrm{K}^{+}, \mathrm{Cl}^{-}\right)$proceed concertedly via highly synchronous transition states, therefore resembling the corresponding process involving the parent $\mathrm{C}_{60^{-}}$ fullerene. However, a significant enhancement of the Diels-Alder reactivity is found for those systems having an endohedral cation whereas a clear reduction of the reactivity is observed when an anion is encapsulated into the $\mathrm{C}_{60}$-cage. According to the combined ASM-EDA(NOCV) method, the interaction energy between the deformed reactants along the reaction coordinate constitutes the sole factor governing the reactivity of these $\mathrm{M} @ \mathrm{C}_{60}$ species. Thus, cationic systems exhibit a much stronger interaction than the free $\mathrm{C}_{60}$, whereas the behavior of anionic compounds is the opposite. This stronger interaction is mainly the result of higher orbital attractions between the reactants (and less destabilizing Pauli repulsion, albeit to a much lesser extent), which in turn, derives from a stronger $\pi$ (diene) $\rightarrow \pi^{*}$ (fullerene) molecular orbital interaction. At variance to these mono-cationic species, the analogous Diels-Alder reactions involving multiplycharged fullerenes $\mathrm{M@C}_{60}\left(\mathrm{M}=\mathrm{Be}^{2+}, \mathrm{Mg}^{2+}, \mathrm{Al}^{3+}\right)$ proceed stepwise via stable zwitterionic intermediates. This differential behavior may be ascribed to the fact that the higher polarization of the cage promotes an asymmetric approach and, therefore, a

low barrier for the formation of one $\mathrm{C}-\mathrm{C}$ bond preceding the formation of the next one.

In summary, our results firmly establish that the exohedral reactivity of fullerenes can be tuned by the encapsulation of ions inside the cage, which is of crucial importance for the future preparation of new species having different electronic/optical properties.

\section{Acknowledgements}

We are grateful for financial support from the Spanish MINECOFEDER (Grants CTQ2013-44303-P, CTQ2016-78205-P and CTQ2014-51912-REDC to I. F. and CTQ2014-54306-P to M. S.), the Netherlands Organization for Scientific Research (NWO), and Catalan DIUE (projects 2014SGR931, ICREA Academia 2014 prize, and XRQTC to M. S.). The FEDER grant UNGI10-4E-801 has also funded this research. Y. G.-R. acknowledges the MINECO for a FPI grant.

Keywords: fullerene $\cdot$ cations $\cdot$ reactivity $\cdot$ Diels-Alder $\bullet$ Density Functional Theory

[1] a) "Endofullerenes: A New Family of Carbon Clusters": T. Akasaka, S. Nagase, Developments in Fullerene Science, Kluwer, Dordrecht, 2002 chap. 4 and 5; b) S. Guha, K. Nakamoto, Coord. Chem. Rev. 2005, 249, 1111 ; c) N. Martín, Chem. Commun. 2006, 2093; d) Fullerenes. Principles and Applications, (Eds. F. Langa and J.-F. Nierengarten,), RSC: Cambridge, 2011.

[2] For recent reviews on metallofullerenes, see: a) S. Osuna, M. Swart, M. Solà, Phys. Chem. Chem. Phys. 2011, 13, 3585; b) A. Rodríguez-Fortea, A. L. Balch, J. M. Poblet, Chem. Soc. Rev. 2011, 40, 3551; c) A. A. Popov, S. Yang, L. Dunsch, Chem. Rev. 2013, 113, 5989; d) X. Lu, L. Bao, T. Akasaka, S. Nagase, Chem. Commun. 2014, 50, 14701; e) M. GarciaBorràs, S. Osuna, J. M. Luis, M. Swart, M. Solà, Chem. Soc. Rev. 2014, 43, 5089.

[3] J. R. Heath, S. C. Obrien, Q. Zhang, Y. Liu, R. F. Curl, H. W. Kroto, F. K. Tittel, R. E. Smalley, J. Am. Chem. Soc. 1985, 107, 7779.

[4] a) S. Aoyagi, E. Nishibori, H. Sawa, K. Sugimoto, M. Takata, Y. Miyata, R. Kitaura, H. Shinohara, H. Okada, T. Sakai, Y. Ono, K. Kawachi, K. Yokoo, S. Ono, K. Omote, Y. Kasama, S. Ishikawa, T. Komuro, H. Tobita, Nat. Chem. 2010, 2, 678; b) S. Fukuzumi, K. Ohkubo, Y. Kawashima, D. S. Kim, J. S. Park, A. Jana, V. M. Lynch, D. Kim, J. L. Sessler, J. Am Chem. Soc. 2011, 133, 15938; c) S. Aoyagi, Y. Sado, E. Nishibori, H. Sawa, H. Okada, H. Tobita, Y. Kasama, R. Kitaura, H. Shinohara, Angew. Chem., Int. Ed. 2012, 51, 3377; d) H. Okada, T. Komuro, T. Sakai, Y. Matsuo, Y. Ono, K. Omote, K. Yokoo, K. Kawachi, Y. Kasama, S. Ono, R. Hatakeyama, T. Kaneko, H. Tobita, RSC Adv. 2012, 2, 10624.; e) H. Ueno, K. Kokubo, Y. Nakamura, K. Ohkubo, N. Ikuma, H. Moriyama, S. Fukuzumi, T. Oshima, Chem. Commun. 2013, 49, 7376.

[5] H, Ueno, T. Nishihara, Y. Segawa, K. Itami, Angew. Chem. Int. Ed. 2015 , $54,3707$.

[6] H. Reis, O. Loboda, A. Avramopoulos, M. G. Papadopoulos, B. Kirtman, J. M. Luis, R. Zaleśny, J. Comput. Chem. 2011, 32, 908.

[7] H. Suzuki, M. Ishida, M. Yamashita, C. Otani, K. Kawachi, Y. Kasama, E. Kwon, Phys. Chem. Chem. Phys. 2016, 18, 31384.

[8] K. Ohkubo, N. Kohno, Y. Yamada, S. Fukuzumi, Chem. Commun. 2015, 51,8082

[9] H. Ueno, S. Aoyagi, Y. Yamazaki, K. Ohkubo, N. Ikuma, H. Okada, T. Kato, Y. Matsuo, S. Fukuzumi, K. Kokubo, Chem. Sci. 2016, 7, 5770. 
[10] a) H. Kawakami, H. Okada, Y. Matsuo, Org. Lett. 2013, 15, 4466; b) H. Ueno, H. Kawakami, K. Nakagawa, H. Okada, N. Ikuma, S. Aoyagi, K. Kokubo, Y. Matsuo, T. Oshima, J. Am. Chem. Soc. 2014, 136, 11162.

[11] Y. Kawashima, K. Ohkubo, S. Fukuzumi, Chem. Asian J. 2015, 10, 44.

[12] See, for instance: a) S. D. Kahn, C. F. Pau, L. E. Overman, W. J. Hehre, J. Am. Chem. Soc. 1986, 108, 7381; b) C. Spino, H. Rezaei, Y. L. Dory, J. Org. Chem. 2004, 69, 757; c) B. R. Ussing, C. Hang, D. A. Singleton J. Am. Chem. Soc. 2006, 128, 7594; d) D. H. Ess, G. O. Jones, K. N Houk, Adv. Synth. Catal. 2006, 348, 2337; e) A. Talbot, D. Devarajan, S J. Gustafson, I. Fernández, F. M. Bickelhaupt, D. H. Ess, J. Org. Chem. 2015, 80, 548

[13] a) F. M. Bickelhaupt, J. Comput. Chem. 1999, 20, 114. For reviews, see: b) W.-J. van Zeist, F. M. Bickelhaupt, Org. Biomol. Chem. 2010, 8, 3118 c) I. Fernández, F. M. Bickelhaupt, Chem. Soc. Rev. 2014, 43, 4953; d) L. P. Wolters, F. M. Bickelhaupt, WIREs Comput. Mol. Sci., 2015, 5, 324. See also, e) I. Fernández, in Discovering the Future of Molecular Sciences; B. Pignataro, Ed.; pp. 165-187, Wiley-VCH: Weinheim, 2014.

[14] For reviews on the EDA method, see: a) F. M. Bickelhaupt, E. J. Baerends, in Reviews in Computational Chemistry, (Eds. K. B. Lipkowitz, D. B. Boyd), Wiley-VCH: New York, 2000, Vol. 15, pp. 1-86; b) M. von Hopffgarten, G. Frenking, WIREs Comput. Mol. Sci. 2012, 2, 43.

[15] Representative examples: a) A. P. Bento, F. M. Bickelhaupt, J. Org. Chem. 2007, 72, 2201; b) A. P. Bento, F. M. Bickelhaupt, J. Org. Chem. 2008, 73, 7290; c) I. Fernández, F. P. Cossío, F. M. Bickelhaupt, J. Org Chem. 2011, 76, 2310; d) I. Fernández, F. M. Bickelhaupt, F. P. Cossío Chem. Eur. J. 2012, 18, 12395; e) I. Fernández, Phys. Chem. Chem. Phys. 2014, 16, 7662; f) I. Fernández, F. M. Bickelhaupt, J. Comput Chem. 2014, 35, 371; g) I. Fernández, F. M. Bickelhaupt, F. P. Cossío, Chem. Eur. J. 2014, 20, 10791; h) I. Fernández, F. P. Cossío, J. Comput. Chem. 2016, 37, 1265; i) I. Fernández, F. M. Bickelhaupt, Chem. Asian J. 2016, 11, 3297; j) D. Yepes, P. Jaque, I. Fernández, Chem. Eur. J. 2016, 22, 18801

[16] a) W.-J. van Zeist, F. M. Bickelhaupt, Dalton Trans. 2011, 40, 3028, and references therein; b) L. P. Wolters, F. M. Bickelhaupt, ChemistryOpen, 2013, 2, 106; c) A. G. Green, P. Liu, C. A. Merlic, K. N. Houk, J. Am Chem. Soc. 2014, 136, 4575; d) I. Fernández, L. P. Wolters, F. M. Bickelhaupt, J. Comput. Chem. 2014, 35, 2140; e) E. D. Sosa Carrizo, F M. Bickelhaupt, I. Fernández, Chem. Eur. J. 2015, 21, 14362; f) Y García-Rodeja, I. Fernández, Organometallics 2017, 36, 460.

[17] a) I. Fernández, M. Solà, F. M. Bickelhaupt, Chem. Eur. J. 2013, 19, 7416; b) Y. García-Rodeja, M. Solà, I. Fernández, J. Org. Chem. 2017, 82, 754.

[18] a) I. Fernández, M. Solá, F. M. Bickelhaupt, J. Chem. Theory Comput. 2014, 10, 3863; b) F. M. Bickelhaupt, M. Solà, I. Fernández, Chem. Eur. J. 2015, 21, 5760 .

[19] a) Y. García-Rodeja, M. Solà, F. M. Bickelhaupt, I. Fernández, Chem. Eur. J. 2016, 22, 1368; b) Y. García-Rodeja, M. Solà, I. Fernández, Chem. Eur. J. 2016, 22, 10572; c) Y. García-Rodeja, I. Fernández, Chem. Eur. J. 2017, doi: 10.1002/chem.201700551.

[20] a) C.-X. Cui, Y.-J. Liu, J. Phys. Chem. A 2015, 119, 3098; b) D. Zhang, H. Li, H. Wang, L. Li, Int. J. Quantum Chem. 2016, 116, 1846. For a recent study on the addition reactions of transition metal compounds to $\mathrm{Li}^{+} @ \mathrm{C}_{60}$, see: (c) M.C. Yang, A. K. Sharma, W. M. C. Sameera, K. Morokuma, M.-D. Su, J. Phys. Chem. A 2017, doi: 10.1021/acs.jpca.7b01086.

[21] Gaussian 03, Revision E.01, M. J. Frisch, G. W. Trucks, H. B. Schlegel, G. E. Scuseria, M. A. Robb, J. R. Cheeseman, J. A. Montgomery, Jr., T. Vreven, K. N. Kudin, J. C. Burant, J. M. Millam, S. S. Iyengar, J. Tomasi, V. Barone, B. Mennucci, M. Cossi, G. Scalmani, N. Rega, G. A Petersson, H. Nakatsuji, M. Hada, M. Ehara, K. Toyota, R. Fukuda, J. Hasegawa, M. Ishida, T. Nakajima, Y. Honda, O. Kitao, H. Nakai, M. Klene, X. Li, J. E. Knox, H. P. Hratchian, J. B. Cross, V. Bakken, C. Adamo, J. Jaramillo, R. Gomperts, R. E. Stratmann, O. Yazyev, A. J.
Austin, R. Cammi, C. Pomelli, J. W. Ochterski, P. Y. Ayala, K. Morokuma, G. A. Voth, P. Salvador, J. J. Dannenberg, V. G. Zakrzewski, S. Dapprich, A. D. Daniels, M. C. Strain, O. Farkas, D. K. Malick, A. D. Rabuck, K. Raghavachari, J. B. Foresman, J. V. Ortiz, Q. Cui, A. G. Baboul, S Clifford, J. Cioslowski, B. B. Stefanov, G. Liu, A. Liashenko, P. Piskorz, I. Komaromi, R. L. Martin, D. J. Fox, T. Keith, M. A. Al-Laham, C. Y. Peng A. Nanayakkara, M. Challacombe, P. M. W. Gill, B. Johnson, W. Chen, M. W. Wong, C. Gonzalez, J. A. Pople, Gaussian, Inc., Wallingford CT 2004.

[22] R. Ahlrichs, M. Bär, M. Häser, H. Horn, C. Kölmel, Chem. Phys. Lett. 1989, 162, 165

[23] a) A. D. Becke, Phys. Rev. A 1988, 38, 3098; b) J. P. Perdew, Phys. Rev. B 1986, 33, 8822

[24] F. Weigend, R. Ahlrichs, Phys. Chem. Chem. Phys. 2005, 7, 3297.

[25] S. Grimme, J. Antony, S. Ehrlich, H. Krieg, J. Chem. Phys. 2010, 132, 154104.

[26] K. Eichkorn, O. Treutler, H. Öhm, M. Häser, R. Ahlrichs, Chem. Phys. Lett. 1995, 242, 652

[27] C. González, H. B. Schlegel, J. Phys. Chem. 1990, 94, 5523

[28] Y. Zhao, D. G. Truhlar Theor. Chem. Acc. 2008, 120, 215.

[29] Selected examples from the Houk group: a) D. H. Ess, K. N. Houk, J. Am. Chem. Soc. 2007, 129, 10646; b) D. H. Ess, K. N. Houk, J. Am. Chem. Soc. 2008, 130, 10187; c) D. N. Kamber, L. A. Nazarova, Y. Liang, S. A Lopez, D. M. Patterson, H.-W. Shih, K. N. Houk, J. A. Prescher, J. Am Chem. Soc. 2013, 135, 13680; d) J. M. Medina, J. L. Mackey, N. K. Garg, K. N. Houk, J. Am. Chem. Soc. 2014, 136, 15798.

[30] M. Mitoraj, A. Michalak, J. Mol. Model. 2007, 13, 347.

[31] M. P. Mitoraj, A. Michalak, T. Ziegler, J. Chem. Theory Comput. 2009, 5, 962.

[32] E. J. Baerends, J. Autschbach, A. Berces, J. A. Berger, F. M. Bickelhaupt, C. Bo, P. L. de Boeij, P. M. Boerrigter, L. Cavallo, D. P. Chong, L. Deng R. M. Dickson, D. E. Ellis, M. van Faassen, L. Fan, T. H. Fischer, C. Fonseca Guerra, S. J. A. van Gisbergen, J. A. Groeneveld, O. V Gritsenko, M. Grüning, F. E. Harris, P. van den Hoek, C. R. Jacob, H. Jacobsen, L. Jensen, E. S. Kadantsev, G. van Kessel, R. Klooster, F. Kootstra, E. van Lenthe, D. A. McCormack, A. Michalak, J. Neugebauer, V. P. Nicu, V. P. Osinga, S. Patchkovskii, P. H. T. Philipsen, D. Post, C. C. Pye, W. Ravenek, P. Romaniello, P. Ros, P. R. T. Schipper, G. Schreckenbach, J. Snijders, M. Solà, M. Swart, D. Swerhone, G. te Velde, P. Vernooijs, L. Versluis, L. Visscher, O. Visser, F. Wang, T. A. Wesolowski, E. M. van Wezenbeek, G. Wiesenekker, S. K. Wolff, T. K. Woo, A. L. Yakovlev, T. Ziegler, Computer Code ADF 2016.01; Scientific Computing and Modeling NV: Amsterdam, The Netherlands http://www.scm.com

[33] See http://www.scm.com for further details.

[34] a) E. van Lenthe, E. J. Baerends, J. G. Snijders, J. Chem. Phys. 1993, 99, 4597; b) E. van Lenthe, E. J. Baerends, J. G. Snijders, J. Chem. Phys. 1994, 101, 9783; c) E. van Lenthe, A. Ehlers, E. J. Baerends, J. Chem. Phys. 1999, 110, 8943.

[35] a) Y. Noguchi, O. Sugino, H. Okada, Y. Matsuo J. Phys. Chem. C 2013, 117,15362

[36] W. P. Jencks, Chem. Rev. 1985, 85, 511

[37] a) G. S. Hammond, J. Am. Chem. Soc. 1955, 77, 334; b) A. Pross, in Theoretical and Physical Principles in Organic Reactivity; Wiley: New York, 1995.

[38] E. E. Maroto, J. Mateos, M. Garcia-Borràs, S. Osuna, S. Filippone, M. Á. Herranz, Y. Murata, M. Solà, N. Martín, J. Am. Chem. Soc. 2015, 137, 1190

[39] Unfortunately, we were not able to locate the TS1 for the reaction involving $\mathrm{Al}^{3+} @ \mathrm{C}_{60}$, which is not surprising considering the high stability of the corresponding zwitterionic intermediate and the rather low barrier associated with this $\mathrm{C}-\mathrm{C}$ bond formation. 
Entry for the Table of Contents (Please choose one layout)

Layout 1:

\section{FULL PAPER}

\section{Tuning the Reactivity: The}

encapsulation of an ion inside the $\mathrm{C}_{60^{-}}$ fullerenic cage has a tremendous impact on the exohedral reactivity of the $\mathrm{C}_{60}$ moiety. The origins of the observed reactivity trend (see Figure) has been quantitatively explored in detail by means of Density Functional Theory calculations.

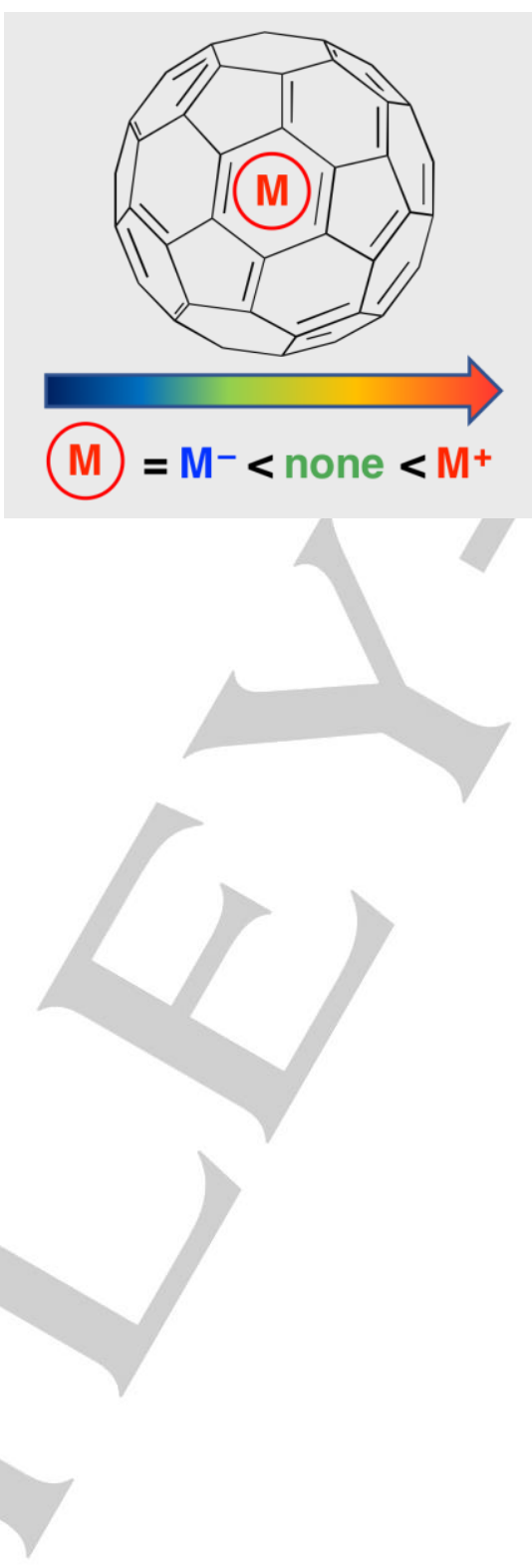

Yago García-Rodeja, Miquel Solà, F. Matthias Bickelhaupt, and Israel Fernández*

Page No. - Page No.

Understanding the Reactivity of lonEncapsulated Fullerenes 